\title{
E_Breast: A Computerized Database Management System for Breast Diseases Patients in a Low Income Country
}

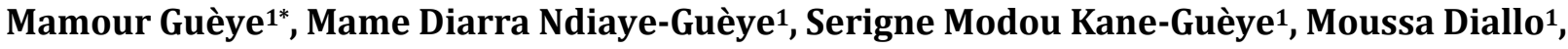 \\ Mor Cissé1, Khalifa Fall1, Hadja Maimouna Barro Daff', Mihimit Abdoulaye1, Sylvestre Gahungu1, \\ Sidy Ka², Jean Charles Moreau ${ }^{1}$
}

\author{
${ }^{1}$ Gynecologic and Obstetric Clinic, Aristide Le Dantec Teaching Hospital, Dakar, Senegal \\ ${ }^{2}$ Oncology Clinic, Aristide Le Dantec Teaching Hospital, Dakar, Senegal \\ Email: *mamourmb@yahoo.fr
}

How to cite this paper: Guèye, M., NdiayeGuèye, M.D, Kane-Guèye, S.M., Diallo, M., Cissé, M., Fall, K., Daff, H.M.B., Abdoulaye, M., Gahungu, S., Ka, S. and Moreau, J.C. (2016) E_Breast: A Computerized Database Management System for Breast Diseases Patients in a Low Income Country. Open Journal of Obstetrics and Gynecology, 6, 754-760.

http://dx.doi.org/10.4236/ojog.2016.612093

Received: September 15, 2016 Accepted: November 21, 2016

Published: November 24, 2016

Copyright $\odot 2016$ by authors and Scientific Research Publishing Inc. This work is licensed under the Creative Commons Attribution International License (CC BY 4.0).

http://creativecommons.org/licenses/by/4.0/

\section{(c) (i) Open Access}

\begin{abstract}
Objectives: To report our experience in using an electronic database for management of breast diseases in a developing country. Materials and methods: E-Breast is a database developed on FileMaker Pro Advanced to serve as patient file and breast diseases registry. The development of the platform, its usage and advantages on a manual filing system are described. Results: For 6 years, we use this database, which accounts more than 2000 patients and includes data from more than 10 years. An overview of the activity is easily generated by E-Breast. The generated reports are used to the routine care of patients, statistics and clinical research. Data entered are immediately useful in addition to simultaneously implement the database for clinical research. Many custom features are integrated. For research purposes, the system has the ability to perform detailed analyses on subsets defined by the user as breast cancer, breast benign diseases, etc. Conclusion: E-Breast has proven to be a useful way of documentation that has become an integral and essential part of the daily activity and also a valuable research tool.
\end{abstract}

\section{Keywords}

E_Breast, Breast, Electronic Medical Record, Senegal

\section{Introduction}

Medical information needed for clinical decision-making has increased. However, the organization and accessibility of health data are still poor, resulting in inappropriate 
decisions and medical errors [1] [2]. To increase the accessibility and management of medical information, the use of informatics tools has been promoted [3].

If the computerization of medical records is growing trend in Western countries, it is lagging behind in our regions; chronologically, decades separate us.

Several medical data management systems are commercially available; their relatively high cost has led us to develop a customized database for monitoring clinical activity of a Breast Unit: E-Breast, a program created with FileMaker Pro Advanced Inc.

This study reports our experience in the use of this platform from 2010 to 2015 by giving examples of its remarkable potential for the analysis of clinical data.

\section{Methods}

This study took place in a Breast Unit of Aristide Le Dantec Teaching Hospital in Dakar Senegal. In 2010, E_Breast based on FileMaker Pro 7.0 (FileMaker Inc., Santa Clara, California, USA) was developed. Data from all patients with breast concerns were entered into the database.

The database requires username and password in order to gain access into the system and dates of creation, modifications and updates are indicated.

The central node of the E-Breast system resides on a server located in a central location within the department. A wireless LAN (Local Area Network) allows users to use multiple computers and devices simultaneously. Several computers in the clinic are then linked together to allow transfer reports or data. This provides a feature that can quickly view, retrieve, update and modify the database. Data storage is unlimited.

All the data are stored in the permanent database with back-ups.

Feature allows user to insert the new patient data during patient registration.

For each patient with diagnosis of breast cancer, a linked record is then created where tumor-characteristics (tumor site, tumor stage according to the TNM system, primary involvement of the lymph nodes or distant metastases, histology) were entered.

Automatic calculation tools are inserted to assist data analysis and output graphs that are plotted automatically.

Others tables are also linked to patient's information as "Media data" (Figure 1). The media data table can store various media data as scans, movies or pdf files.

\section{Results}

All these data could be moved to Excel or SPSS for complex statistical analysis. All graphs presented here are exclusively made with E_Breast.

Since January 2010, more than 2000 patients and 7000 visits have been recorded into the database. The records included all epidemiological, clinical and treatment information of patients.

Patient data were entered into the medical records and into the database. For retrospective records, data were extracted from the patient's file and entered into the database. This task was usually often done by a medical assistant.

Medical data were entered by doctors during the medical examination. Several drop- 


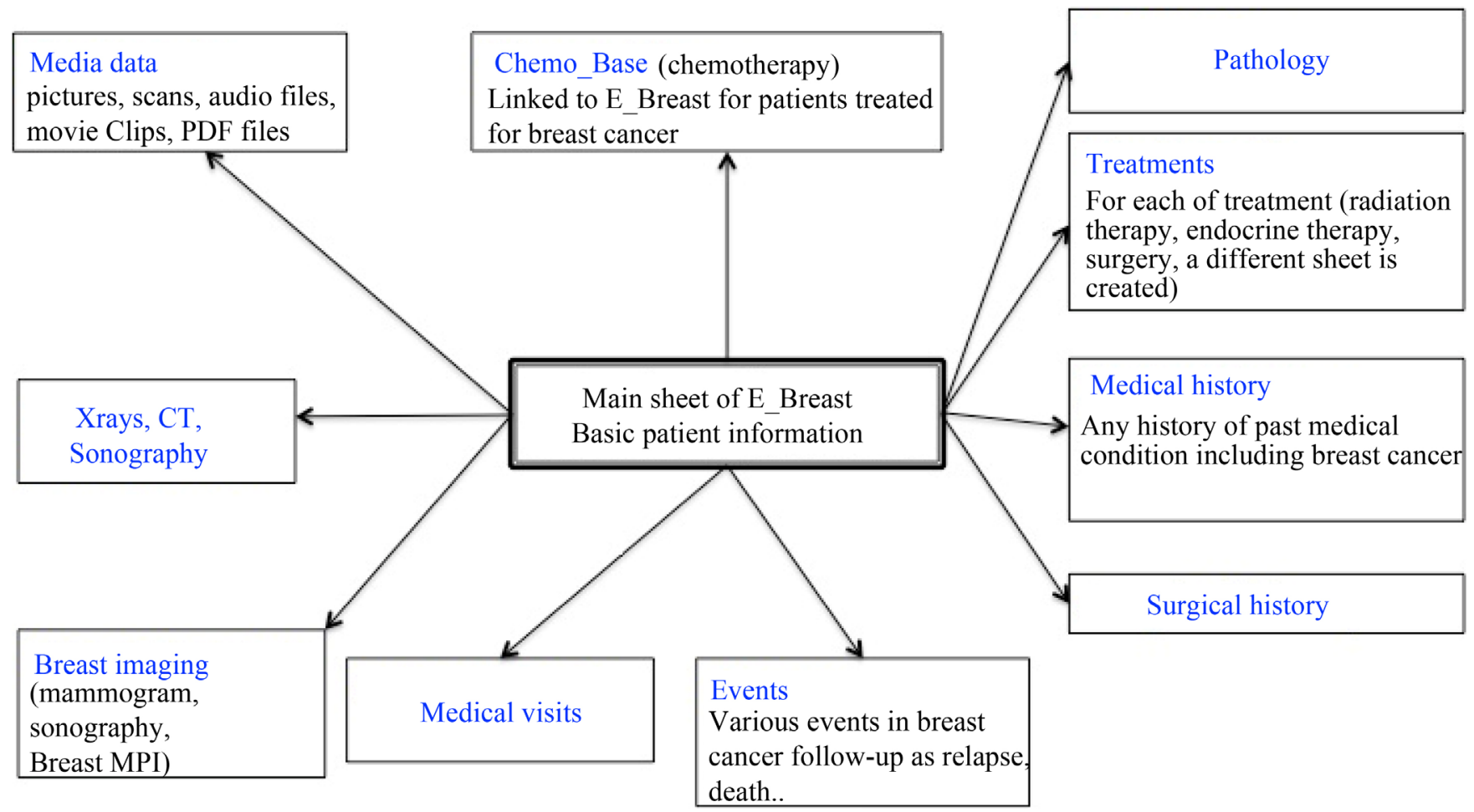

Figure 1. E_Breast structure.

down menus were available which reduced the free text typing.

The next follow-up visit was scheduled at the end of the current visit directly into the database via the appointment module.

The possibility to store the program in a server offered good access to information from any location of the department and from any device (computer or iPhone/iPad) from which data could be entered, modified or updated.

Regular backups were scheduled at various times of the day that ensured data security.

Complex queries were easily set in motion through automation by powerful scripts. Some charts are provided in Figure 2 showing how information could be obtained using graph layout via drop down menus.

\section{Discussion}

\subsection{Why Using FileMaker?}

Several medical data management systems were developed and are commercially available [4]-[11].

E_Breast is an Electronic Medical Record (EMR) system created using FileMaker.

FileMaker was chosen because it was the only application with the necessary set of tools: a client/server application that works in a wireless local area network that could function on Windows or Mac OS laptops, on mobile iOS devices (iPads and iPhones) and a doctor who had expertise in FileMaker. 


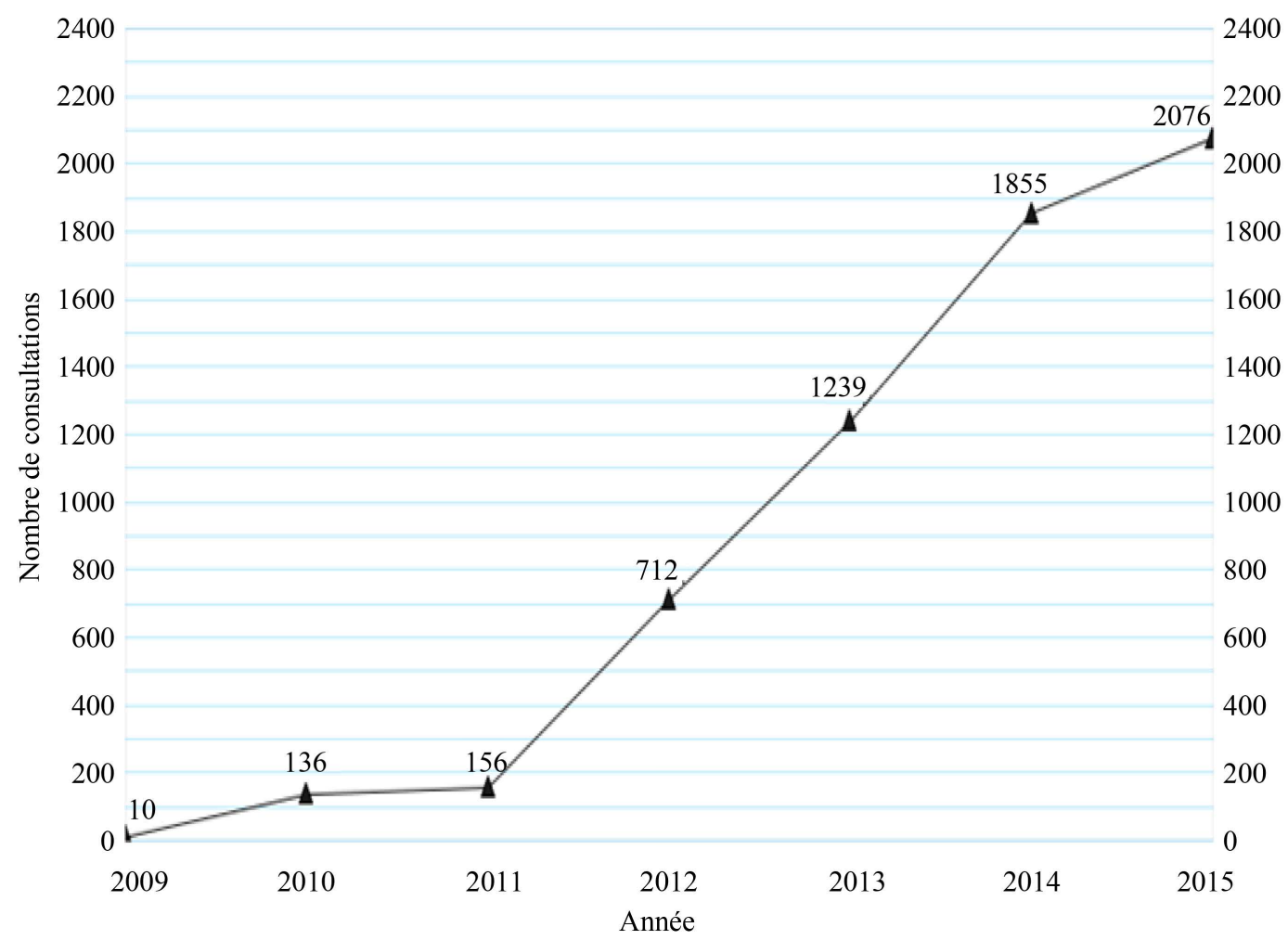

(a)

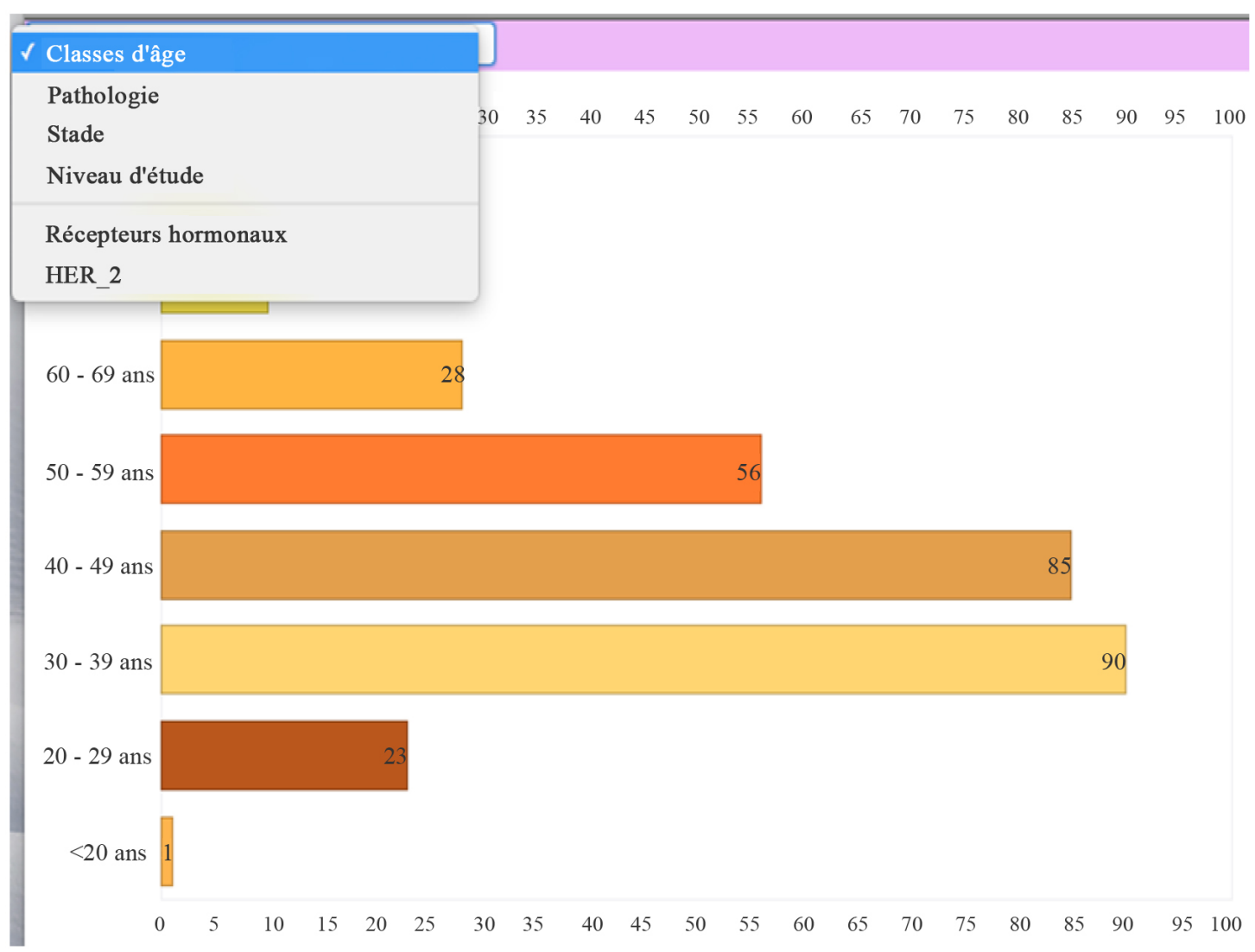

(b) 
HER_2
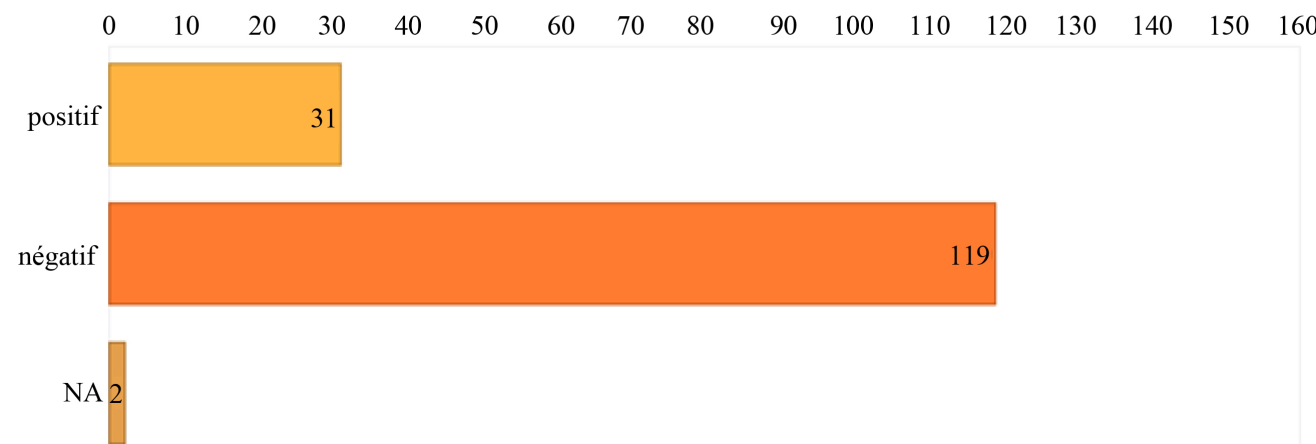

Equivoque 2

$$
\text { | }
$$

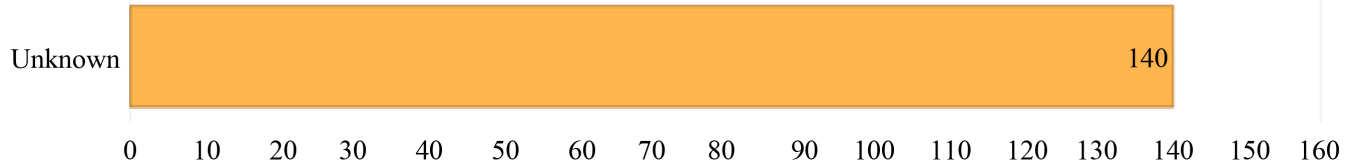

(c)
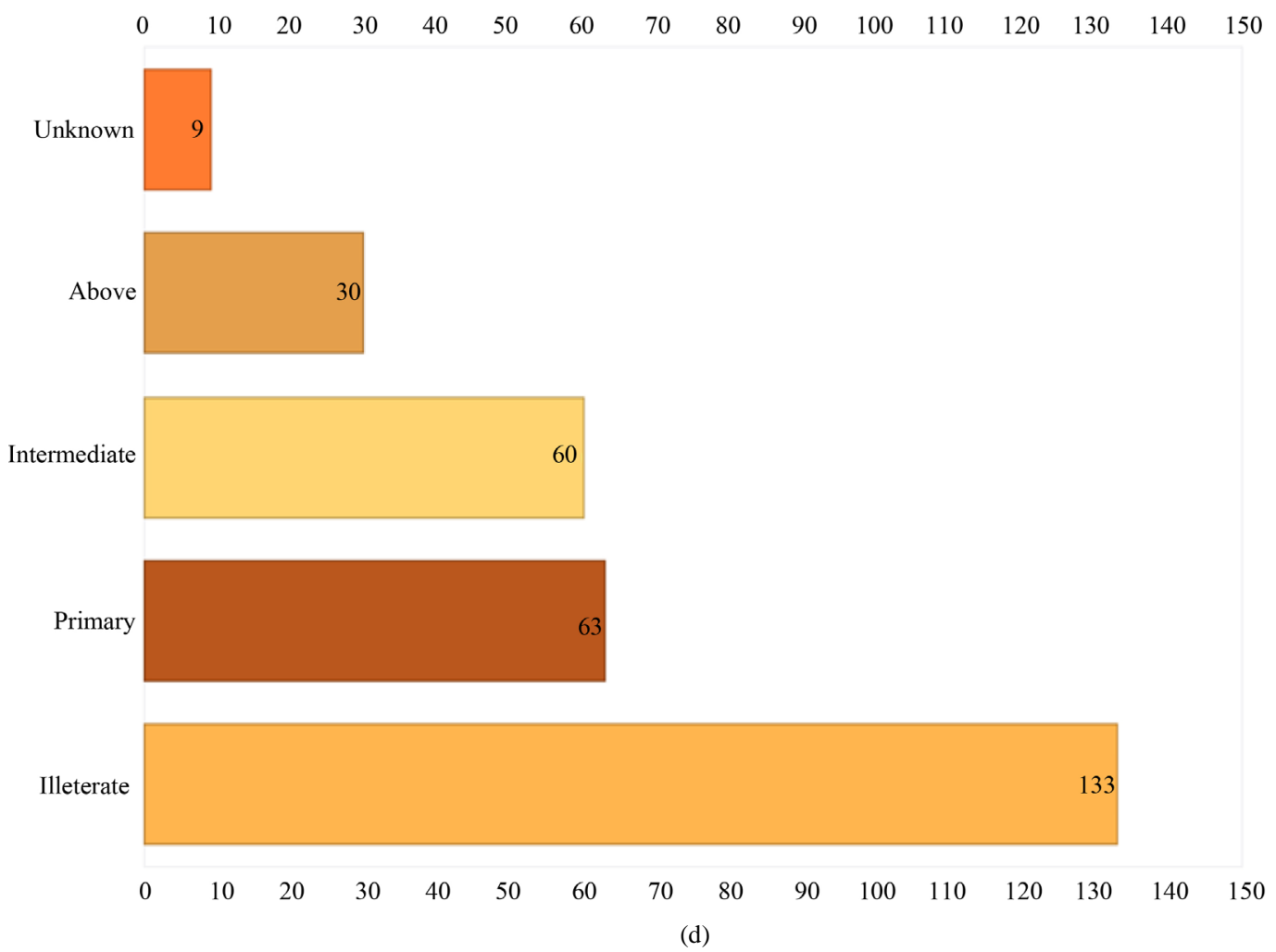

Figure 2. Charts generated by E_Breast. (a) Chart showing yearly admissions; (b) with a drop down menu, this chart can display patients by age group, HER-2 status for breast cancer (c); literacy (d). 
It works on both Macintosh and Windows computers, and is the top-selling database for both platforms. FileMaker databases can be shared simultaneously among multiple users, whether Mac or Windows. FileMaker databases can also be accessed on the iPhone and iPad using the free FileMaker Go app.

\subsection{Benefits of E_Breast}

Unlike other database systems, ours was developed by a doctor and moreover, an obstetrician. The development was primarily guided by clinical experience which helped to anticipate difficulties and optimize the structure of the database for the use of data for statistical and research purposes.

All information is available anytime that can enhance quality of care.

\subsection{E_Breast to Store and Share Research}

Data are prospectively collected and updated. This delivers complete and valid data.

Several statistical predefined analyses are processed. Others complex queries are also possible.

All sheets data can be moved to Excel or SPSS for complex statistical analysis.

Healthcare facilities can benefit from implementing their own research and development software. By consulting with local FileMaker developers, hospitals that also conduct research, can create custom database software that allows them to store and recall critical information and results, and also share this information with other doctors in the network.

By doing this, healthcare providers can create a community that is on the forefront of research and innovation within their field, and also inform fellow physicians and nurses on the latest data available in the field. This can help foster an organization that is innovative and committed to success.

\subsection{Data Management/Data Manager}

Adoption of a data manager is crucial. Depending on the amount of data as well as the complexity of the database system, a dedicated data manager or administrator is mandatory [12]. This task was allocated to the doctor who created and implemented the database. But, it is urgent to train others practitioners interested in the field for a sustainable system.

\section{Conclusion}

To keep millions of information collected, processed, analyzed and exchanged, it is necessary today, databases, which necessarily involves computerizing patient records.

\section{Acknowledgements}

We would like to acknowledge some persons who help us during the process: Ms. Louise MENDY, Ms. Astou SARRE, Ms. Bintou NGOM, Ms. Maguette SYLLA, Ms. Rokhaya NDAO, Ms. Thiame Sarr Kamara TOURE. 


\section{References}

[1] Tierney, W. (2001) Improving Clinical Decisions and Outcomes with Information: A Review. International Journal of Medical Informatics, 62, 1-9. https:/doi.org/10.1016/S1386-5056(01)00127-7

[2] (1886) TRW Uses AI Tools to Control System Problems. Aviation Week \& Space Technology, 79-81.

[3] Bleich, H., Beckley, R. and Horowitz, G. (1985) Clinical Computing in a Teaching Hospital. The New England Journal of Medicine, 312, 756-764. https:/doi.org/10.1056/NEJM198503213121205

[4] Benjamin, I., Noumoff, J.S., Carlson Jr., J.A., Giuntoli, R.L., Morgan, M. and Mikuta, J.J. (1990) Database Management for a Gynecologic Oncology Service. Gynecologic Oncology, 38, 431-436. https:/doi.org/10.1016/0090-8258(90)90086-Z

[5] Raab, G. and van Den Bergh, M. (2001) Development and Integration of the Oncological Documentation System ODS. Zentralbl Gynakol, 128, 444-449. https:/doi.org/10.1055/s-2001-17241

[6] Salenius, S.A., Margolese-Malin, L., Tepper, J.E., Rosenman, J., Varia, M. and Hodge, L. (1992) An Electronic Medical Record System with Direct Data-Entry and Research Capabilities. International Journal of Radiation Oncology Biology Physics, 24, 369-376. https:/doi.org/10.1016/0360-3016(92)90693-C

[7] Jacob, R. and Welkoborsky, H.J. (2002) Presentation of an Oncological Database Adapted for Head and Neck Cancer. Laryngorhinootologie, 81, 875-881. https:/doi.org/10.1055/s-2002-36104

[8] Poorten, V.V., Hart, A., Vauterin, T., Jeunen, G., Schoenaers, J., Hamoir, M., et al. (2009) Prognostic Index for Patients with Parotid Carcinoma: International External Validation in a Belgian-German Database. Cancer, 115, 540-550. https:/doi.org/10.1002/cncr.24015

[9] Mira, E., Lanza, L., Castelli, A., Benazzo, M. and Tinelli, C. (1998) A Computerized Database for Managing Otorhinolaryngologic Oncology Patients. Acta Otorhinolaryngologica Italica, 18, 155-163.

[10] Landis, S.H., Murray, T., Bolden, S. and Wingo, P.A. (1999) Cancer Statistics. CA: A Cancer Journal for Clinicians, 49, 8-31. https:/doi.org/10.3322/canjclin.49.1.8

[11] Wagenblast, J., Adunka, O., Gstottner, W., Arnoldner, C., Riedl, N., Diensthuber, M., et al. (2010) AdOnco Database-Six Years' Experience with the Documentation of Clinical and Scientific Data on Patients with Head and Neck Cancer. In Vivo, 24, 603-606.

[12] Kufeld, M., Fürweger, C., Drexler, C.G., Wowra, B. and Muacevic, A. (2009) Implementation of a Medical Database System for a Radiosurgery Center. Cureus, 1, e4. 
Submit or recommend next manuscript to SCIRP and we will provide best service for you:

Accepting pre-submission inquiries through Email, Facebook, LinkedIn, Twitter, etc. A wide selection of journals (inclusive of 9 subjects, more than 200 journals)

Providing 24-hour high-quality service

User-friendly online submission system

Fair and swift peer-review system

Efficient typesetting and proofreading procedure

Display of the result of downloads and visits, as well as the number of cited articles

Maximum dissemination of your research work

Submit your manuscript at: http://papersubmission.scirp.org/

Or contact ojog@scirp.org 